\title{
Measurements of transepithelial electrical resistance (TEER) are affected by junctional length in immature epithelial monolayers
}

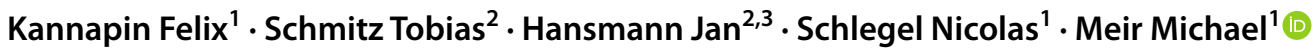

Accepted: 19 August 2021 / Published online: 30 August 2021

(c) The Author(s) 2021

\begin{abstract}
The measurement of transepithelial electrical resistance (TEER) is a common technique to determine the barrier integrity of epithelial cell monolayers. However, it is remarkable that absolute TEER values of similar cell types cultured under comparable conditions show an immense heterogeneity. Based on previous observations, we hypothesized that the heterogeneity of absolute TEER measurements can not only be explained by maturation of junctional proteins but rather by dynamics in the absolute length of cell junctions within monolayers. Therefore, we analyzed TEER in epithelial cell monolayers of Caco2 cells during their differentiation, with special emphasis on both changes in the junctional complex and overall cell morphology within monolayers. We found that in epithelial Caco2 monolayers TEER increased until confluency, then decreased for some time, which was then followed by an additional increase during junctional differentiation. In contrast, permeability of macromolecules measured at different time points as $4 \mathrm{kDA}$ fluorescein isothiocyanate (FITC)-dextran flux across monolayers steadily decreased during this time. Detailed analysis suggested that this observation could be explained by alterations of junctional length along the cell borders within monolayers during differentiation. In conclusion, these observations confirmed that changes in cell numbers and consecutive increase of junctional length have a critical impact on TEER values, especially at stages of early confluency when junctions are immature.
\end{abstract}

Keywords TEER $\cdot$ Barrier models $\cdot$ Impedance spectroscopy $\cdot$ Permeability $\cdot$ Caco 2 cells

\section{Introduction}

Measurements of transepithelial electrical resistance (TEER) are a standard technical approach to assess barrier properties and dynamics of various different in vitro cell culture models. TEER measurements are ideal for time-dependent and nondestructive monitoring of dynamic changes of barrier functions as shown in models of the endothelial barrier

Kannapin Felix and Schmitz Tobias have contributed equally.

Meir Michael

Meir_M@ukw.de

1 Department of General, Visceral, Vascular and Pediatric Surgery, University Hospital Würzburg, Oberduerrbacherstrasse 6, 97080 Würzburg, Germany

2 Department for Tissue Engineering and Regenerative Medicine, University Hospital Würzburg, Roentgenring 11, 97070 Würzburg, Germany

3 Translational Center Regenerative Therapies (TLC-RT), Fraunhofer Institute for Silicate Research ISC, Neunerplatz 2, 97082 Würzburg, Germany
(Schlegel et al. 2012), intestinal epithelial barriers (Meir et al. 2019), pulmonary alveolar epithelial barrier (Rezaee and Georas 2014), or urinary tract epithelial barrier (ProtBertoye and Houillier 2020).

Historically, permeation or diffusion assays were a first approach to investigate the tightness of intercellular junctions (Bowman et al. 1983), where a tracer of defined molecular size was placed on the apical side of a cell monolayer that was grown on a semipermeable membrane. The flux of this tracer through the cell monolayer enabled the quantification of a permeability coefficient (Zelman 1972). Yet, most of the tracers themselves influence barrier properties, and the quantification is limited to certain time points since a continuous measurement is not possible (Duffy and Murphy 2001). The measurement of TEER offers the opportunity to monitor physiological homeostasis as well as pathological conditions in vitro in real time and in a noninvasive manner (Srinivasan et al. 2015).

In our previous work, we focused on mechanisms involved in the regulation of intestinal epithelial barrier function in vitro (Meir et al. 2015; Spindler et al. 2015). The 
intestinal epithelial barrier is maintained by junctional proteins forming the "terminal bar" that seals the paracellular cleft. This terminal bar is formed by circumferential intercellular proteins such as tight junctions or adherens junction proteins that are affected under several pathophysiological conditions (Schulzke et al. 2012; Ivanov and Naydenov 2013). In addition, desmosomes are critical in the regulation of the intestinal barrier (Schlegel et al. 2021).

Traditionally, for in vitro models of the intestinal epithelial barrier, redifferentiated cells from human colon carcinoma such as HT29/B-6 cells (Hering et al. 2017), T84 cells (Sayoc-Becerra et al. 2020), and Caco2 cells (Schlegel et al. 2010) have been used. However, when absolute TEER values expressed in $\Omega$ area were reported in these models, a wide variation of TEER values have been published in the last years even when similar experimental in vitro conditions for identical cell lines were applied. Different factors such as temperature (Blume et al. 2010), the passage number of cells (Briske-Anderson et al. 1997), or the composition of cell culture media (Robilliard et al. 2018) have been identified to influence TEER levels. While these factors can be easily controlled under laboratory conditions, we still observed a great variation of absolute TEER values in our own data especially during the early phase after confluency, in the differentiation phase of the cell monolayer. Based on our observations, we hypothesized that a major impact on absolute TEER measurements is the absolute circumferential length of cellular junctions within monolayers rather than the maturation of junctional proteins and the abovementioned factors.

\section{Materials and methods}

\section{Cell culture}

Two different Caco2 cell lines were used for the experiments. Clone 1 was acquired from the Deutsche Sammlung für Mikroorganismen und Zelllkulturen (Braunschweig, Germany), while clone 2 was acquired from ATCC (Wesel, Germany). Both clones were cultured in Dulbecco's modified medium supplemented with $50 \mathrm{U} / \mathrm{ml}$ penicillin $\mathrm{G}, 50 \mu \mathrm{g}$ streptomycin, and 10\% fetal calf serum (FCS) (Biochrom, Berlin, Germany) in a humidified atmosphere (95\% air $/ 5 \%$ $\mathrm{CO} 2)$ at $37^{\circ} \mathrm{C}$.

\section{Immunocytochemistry}

Immunostaining has been described in detail previously (Meir et al. 2020). In brief, epithelial cells were grown to confluence on coverslips and cultured to different time points as indicated below. Then, cells were fixated with $2 \%$ formaldehyde for $10 \mathrm{~min}$ at room temperature. After treatment with $0.1 \%$ Triton $\mathrm{X}-100$ for $15 \mathrm{~min}$, monolayers were incubated at $4{ }^{\circ} \mathrm{C}$ overnight using the following primary antibodies (1:100 each in PBS): a mouse monoclonal E-cadherin antibody IgG (\# 610182, BD Biosciences, Heidelberg, Germany) and a mouse anti-Desmoglein2 IgG (\# 32-6100, Thermo Fisher Scientific, Waltham, MA, USA), or mouse anti-Claudin 1 IgG (\# 37-4900 Thermo Fisher Scientific, Waltham MA, USA) and rabbit anti-Claudin5 IgG (\# 34-1600 Thermo Fisher Scientific, Waltham MA, USA diluted 1:50 with PBS). As secondary antibodies, we used $\mathrm{Cy} 3$ (indocarbocyanine) labeled goat anti-mouse IgG (diluted 1:600; \# 115-165-003, Dianova Hamburg Germany) or goat anti-rabbit IgG (diluted 1:600; \# 111-165003, Dianova, Hamburg, Germany). Coverslips and filters were mounted on glass slides with Vector Shield Mounting Medium as antifading compound, which included DAPI to counterstain cell nuclei (Vector Laboratories, Burlingham, CA). Representative experiments were photographed with a Keyence digital microscope (Keyence, Osaka, Japan) using a Zeiss lens (Carl-Zeiss Jena, Germany) with a $63 \times$ magnification and TRITC and GFP-BP as well as DAPI-BP filters (all Keyence, Osaka, Japan). Then, the images were taken with a 12.5 megapixel camera and analyzed with BZ-H4A Analysis Software (Keyence, Osaka, Japan).

\section{Measurements of cell number and circumferential junctional length}

To quantify the number of cells and the circumferential junctional length per area during the differentiation, immunostaining with E-cadherin and DAPI was used. For each time point, the number of DAPI-stained nuclei in an area of $0.1 \mathrm{~mm}^{2}$ was counted. To estimate the circumferential junctional length, E-cadherin-stained cell borders were measured with ImageJ (National Institutes of Health, USA) and then divided by the number of cells in the same area of $0.1 \mathrm{~mm}^{2}$ to normalize the measurements.

\section{Measurement of FITC-dextran flux across monolayers of cultured epithelial cells}

Caco 2 cells were seeded on top of transwell filter chambers on 12 -well plates $(0.4 \mu \mathrm{m}$ pore size; Falcon, Heidelberg, Germany) as previously described (Schlegel et al. 2010; Chang et al. 2000). After reaching confluence, cells were rinsed with PBS and incubated with fresh DMEM without phenol red (Sigma) containing $10 \mathrm{mg} / \mathrm{ml}$ FITC-dextran (4 kDa). Paracellular flux was assessed by taking $100 \mu \mathrm{l}$ aliquots from the outer chamber over $2 \mathrm{~h}$ of incubation. Fluorescence was measured using a Tecan GENios Microplate Reader (MTX Lab systems, Bradenton, USA) with excitation and emission at 485 and $535 \mathrm{~nm}$, respectively. For all experimental conditions, permeability coefficients $\left(\mathrm{P}_{\mathrm{E}}\right)$ were 
calculated by the following formula: $\mathrm{P}_{\mathrm{E}}=\frac{\frac{\Delta C_{\mathrm{A}}}{\Delta t} \times V_{A}}{S \times C_{L}}$, where $\mathrm{P}_{\mathrm{E}}=$ diffusive permeability $(\mathrm{cm} / \mathrm{s}), \Delta \mathrm{C}_{\mathrm{A}}=$ change of FITCDextran concentration, $\Delta \mathrm{t}=$ change of time, $V_{A}=$ volume of the abluminal medium, $\mathrm{S}=$ surface area, and $C_{L}=$ constant luminal concentration.

\section{Measurements of transepithelial electrical resistance (TEER)}

ECIS 1600R for clone 1 (Applied BioPhysics) and ECIS ZTheta for clone 2 (Applied BioPhysics) were used to measure TEER of epithelial monolayers to assess epithelial barrier functions at $400 \mathrm{~Hz}$, as described in detail previously (Flemming et al. 2015). The TEER of an empty insert was subtracted from every value. Medium was exchanged every 2 days.

\section{Statistics}

Values are expressed as mean \pm SD. Statistical analyses were performed using GraphPad Prism 7.0 (GraphPad, La Jolla, USA). Origin 2018 (OriginLab Corporation, Northampton, MA, USA) was used for creating graphs. For each experiment, Gaussian distribution was checked by D'Agostino and Pearson normality test. For every experiment, the statistic test used is stated in the figure legends. Statistical significance was assumed for $p<0.05$.

\section{Results and discussion}

\section{Caco2 cells need time to maturate to be considered as a true model of intestinal epithelial barrier function}

First, we characterized the changes of the intestinal epithelial barrier function of two different $\mathrm{Caco} 2$ cell clones during their differentiation at different time points. To identify changes in the expression of junctional barrier proteins, we performed immunostaining. While at confluence both $\mathrm{Caco} 2$ clones showed regular staining patterns of adherens junction protein E-cadherin and desmosomal Desmoglein-2 at the cell borders, tight junction protein Claudin-1 was hardly visible (Fig. 1a, b). After 7 days, clone 1 demonstrated a maturated terminal bar at the cell borders where all junctional proteins including tight junctions were regularly distributed at the cell borders (Fig. 1a). Differentiated barrier maturation occurred earlier when analyzing clone 2 , where a linear staining of tight junction proteins was already present 4 days after confluence (Fig. 1b). The staining pattern of all junctions did not change at later time points (14 days after confluence for clone 1 , and 6 days after confluence for clone 2). Therefore, we considered the time point after 7 days for clone 1 and after 4 days for clone 2 as state of a differentiating barrier.

The differentiation of junctional proteins over time was paralleled by a continuous reduction in the permeability of 4 kDA FITC-dextran in the transwell model. This was revealed by measurements of permeability coefficient $\mathrm{P}_{\mathrm{E}}$ at the day of confluence (confluent), after 7 days (clone 1) or 4 days (clone 2) (differentiating barrier), and 14 days (clone 1 ) or 6 days (clone 2) (full barrier) (Fig. 1c and d). The $\mathrm{P}_{\mathrm{E}}$ at confluence was $3.32 \pm 0.13 \mathrm{~cm} / \mathrm{s} \times 10^{-6}$ for clone 1 and $1.63 \pm 0.26 \mathrm{~cm} / \mathrm{s} \times 10^{-6}$ for clone 2 . $\mathrm{P}_{\mathrm{E}}$ significantly decreased for both cell lines during maturation to $0.31 \pm 0.11 \mathrm{~cm} / \mathrm{s} \times 10^{-6}$ for clone 1 and $0.34 \pm 0.19 \mathrm{~cm} / \mathrm{s} \times 10^{-6}$ for clone 2 , showing comparable $P_{E}$ when the epithelial barrier was differentiated. After 14 days or 6 days, respectively, $\mathrm{P}_{\mathrm{E}}$ was not further altered, indicating full barrier properties at these time points for both clones. In contrast to $\mathrm{P}_{\mathrm{E}}$, measurements of TEER showed a different picture when barrier properties were assessed (Fig. 1e and f). Measurements were started directly after seeding of the cells. TEER of clone 1 increased to $137 \pm 16 \Omega \mathrm{cm}^{2}$, when confluence was reached. Afterwards TEER dropped significantly to $88 \pm 7 \Omega \mathrm{cm}^{2}$ and in the following increased again after 14 days to a final value of $139 \pm 18 \Omega \mathrm{cm}^{2}$. A comparable course of TEER development was observed for clone 2, where TEER initially increased to $87 \pm 2 \Omega \mathrm{cm}^{2}$ and dropped to $49 \pm 4 \Omega \mathrm{cm}^{2}$ after 4 days until TEER again increased to $91 \pm 1 \Omega \mathrm{cm}^{2}$ after day 6 . In summary, despite a continuous stabilization of epithelial barrier function as revealed by measurements of $4 \mathrm{kDa}$ FITC-dextran flux, TEER values under the same conditions are undulating. It is important to note that, although the assessment of the barrier function can be performed by measuring the TEER value as well as by studying the passage of marker molecules, the two experimental approaches depend on different transport mechanisms through the barrier (Zucco et al. 2005). This means that, depending on the status of the cell monolayer, the two techniques may express different levels of observed barrier tightness. While the measurement of permeability of FITCdextran or other non-electrolyte paracellular tracers through the cell monolayer depends on the paracellular water flow and the pore size of the tight junctions, the measurement of the TEER value depends on the ionic conductance of the paracellular pathway (Zucco et al. 2005).

\section{Junctional length of Caco2 cells increased during maturation}

Although cells were confluent, we still noticed an increase in the number of cells and a size reduction of cells during the maturation of $\mathrm{Caco} 2$ monolayers. This was confirmed by counting the number of cells/area at the different time 
a $\begin{array}{lll} & \text { Caco2 clone1 } & \\ \text { confluent } & \begin{array}{l}\text { differentiating } \\ \text { barrier }(+7 d)\end{array} & \text { full barrier } \\ (+14 d)\end{array}$
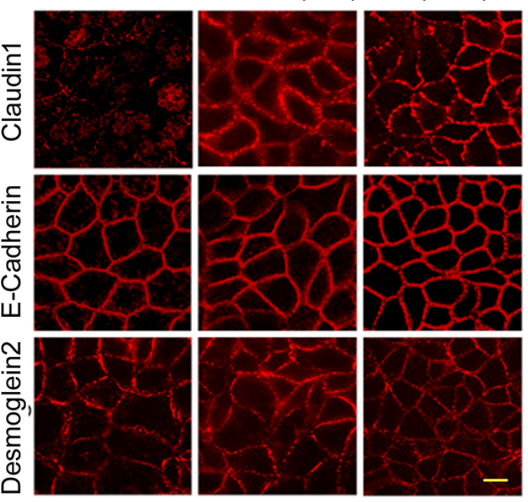

Caco2 clone1

C $P_{E}$ of $4 k D a$ FITC- dextran

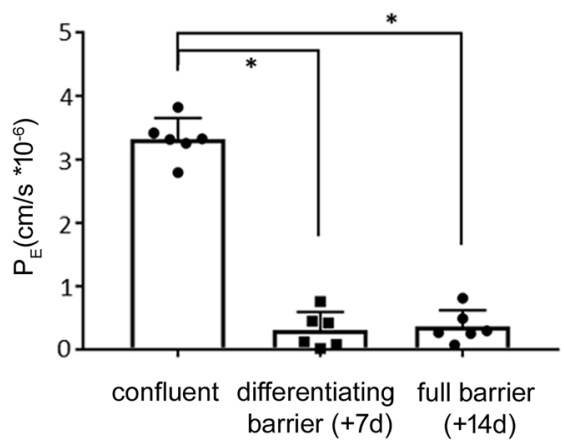

e

Caco2 clone1

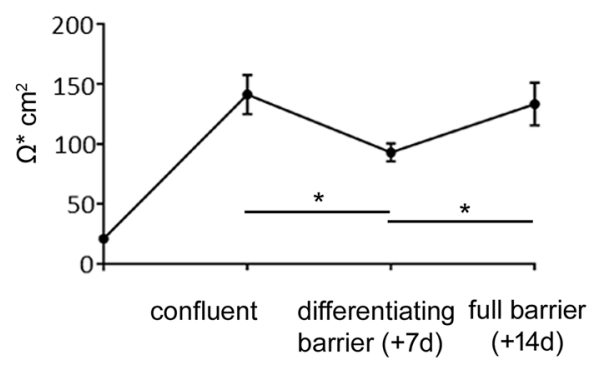

Fig. 1 Differentiation of junctional properties of Caco2 cells. a Representative immunostainings during differentiation of the epithelial barrier of clone 1 are shown. At confluence, in contrast to E-cadherin, junctional proteins Desmoglein-2 (Dsg2) and Claudin-1 were not regularly located at the cell borders. This changed during differentiation of the monolayer to the state of full barrier 14 days later when all junctional proteins showed a regular staining at the cell borders (representatives are shown for $n=6$, scale $20 \mu \mathrm{m}$ ). b Similar observations for the junctional proteins were seen for clone 2 , where tight junction protein Claudin-1 was hardly detectable at the state of confluence but showed a linear staining at the cell borders at the moment of barrier differentiation after 4 days (representatives are shown for $n=6$, scale $20 \mu \mathrm{m}$ ). c. Permeability of $4 \mathrm{kDa}$ FITC-dextran revealed that, with the differentiation of junctional proteins of clone 1 , the permeability coefficient $\left(\mathrm{P}_{\mathrm{E}}\right)$ declined to $(0.31 \pm 0.11) \times 10^{-6} \mathrm{~cm} / \mathrm{s}$ from $(3.32 \pm 0.13) \times 10^{-6} \mathrm{~cm} / \mathrm{s}$ at the state b

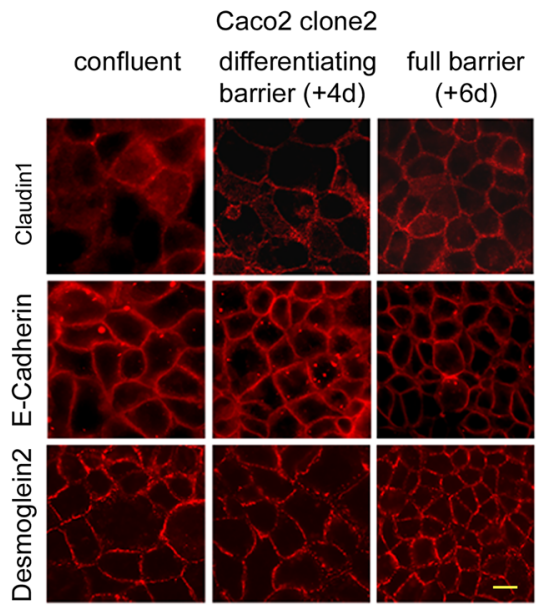

Caco2 clone2

d $P_{E}$ of $4 k D a$ FITC-dextran
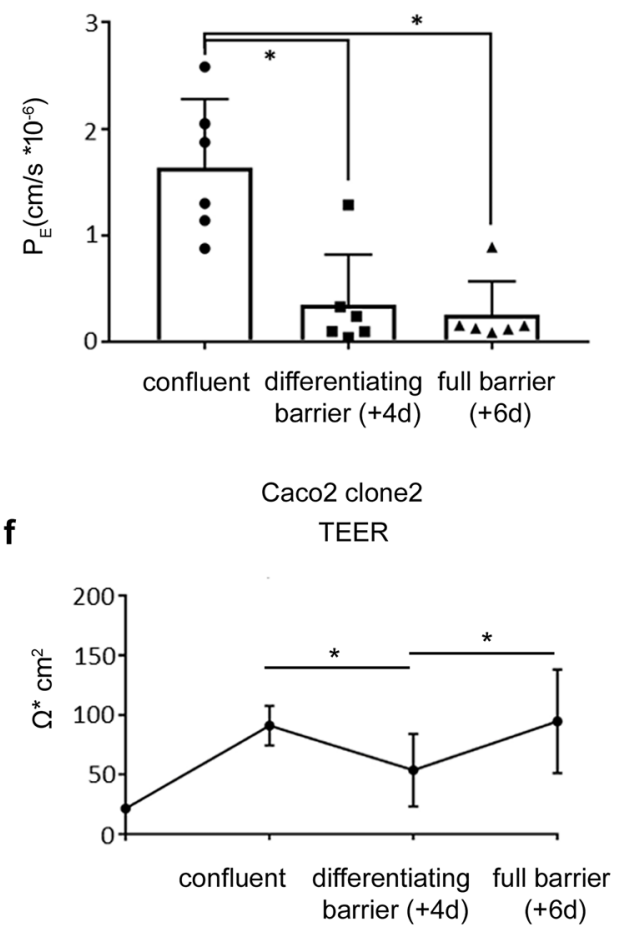

of confluence. This was not further altered under full barrier conditions 21 days after confluence where $P_{E}$ was $(0.36 \pm 0.10) \times 10^{-6} \mathrm{~cm} / \mathrm{s}$ $\left(n=6, * p<0.05\right.$, one-way ANOVA). d. The measurements of $\mathrm{P}_{\mathrm{E}}$ for clone 2 paralleled the development of clone 1 . At confluence, $\mathrm{P}_{\mathrm{E}}$ was $(1.64 \pm 0.26) \times 10^{-6} \mathrm{~cm} / \mathrm{s}$ and dropped to $(0.35 \pm 0.19) \times 10^{-6} \mathrm{~cm} / \mathrm{s}$ 4 days post-confluence, which was not changed at full barrier properties after 6 days $(n=6, * p<0.05$, one-way ANOVA). e. Transepithelial electric resistance (TEER) of clone 1 during the differentiation of the cell monolayer is shown. After seeding, TEER was steadily increasing to $137 \pm 16 \Omega \mathrm{cm}^{2}$. Then, over the next days, TEER decreased to $88 \pm 7 \Omega \mathrm{cm}^{2}$ before it increased again to $139 \pm 18$ $\Omega \mathrm{cm}^{2}$ until the state of full barrier was reached $(n=10, * p<0.05$, two-way ANOVA). $\mathbf{f}$. This change of TEER over the time was almost identical in clone 2 , where TEER rose to $87 \pm 2 \Omega \mathrm{cm}^{2}$ at confluence, dropped during differentiation of the $\mathrm{Caco} 2$ cells, and then increased to $91 \pm 1 \Omega \mathrm{cm}^{2}$ at full barrier ( $n=10, * p<0.05$, two-way ANOVA) 
points: for clone 1 , number of cells $/ 0.1 \mathrm{~mm}^{2}$ increased from $41 \pm 2$ at confluence to $102 \pm 7$ at day 7 to $211 \pm 3$ at day 14 (Fig. 2a). A comparable increase was observed for clone 2, where number of cells $/ 0.1 \mathrm{~mm}^{2}$ augmented from $74 \pm 2$ at confluence to $93 \pm 3$ at day 4 to $117 \pm 3$ at day 6 (Fig. 2b). Given that the absolute contact area between cells changed during cell growth after confluency, we hypothesized that the undulation of TEER after confluence could be explained not only by the maturation of junctional proteins but also by an increase of absolute circumferential junctional length during the differentiation of the enterocytes. The increase of circumferential junctional length was confirmed since average $\mu \mathrm{m}$ junctional length $/ 0.1 \mathrm{~mm}^{2}$ for clone 1 increased from $0.10 \pm 0.02 \mu \mathrm{m} / 0.1 \mathrm{~mm}^{2}$ to $0.22 \pm 0.04 \mu \mathrm{m} / 0.1 \mathrm{~mm}^{2}$ (Fig. 2c) after 14 days, and from $0.16 \pm 0.03 \mu \mathrm{m} / 0.1 \mathrm{~mm}^{2}$ to $0.24 \pm 0.05 \mu \mathrm{m} / 0.1 \mathrm{~mm}^{2}$ for clone 2 (Fig. 2e).

a

Caco2 clone1

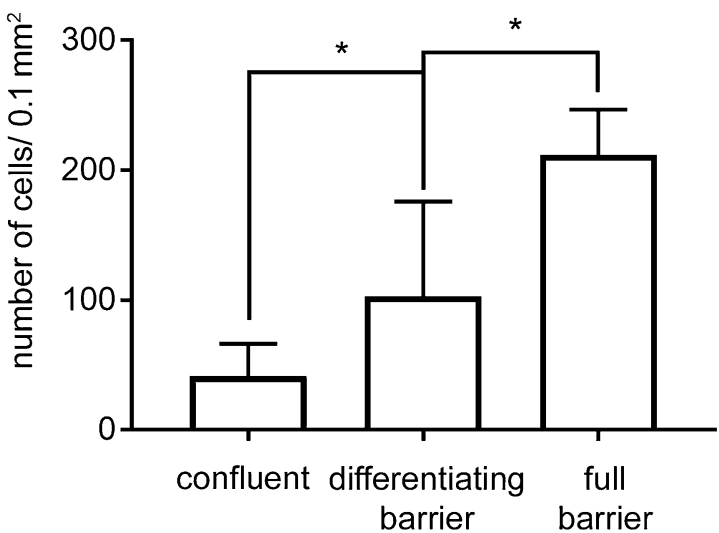

c

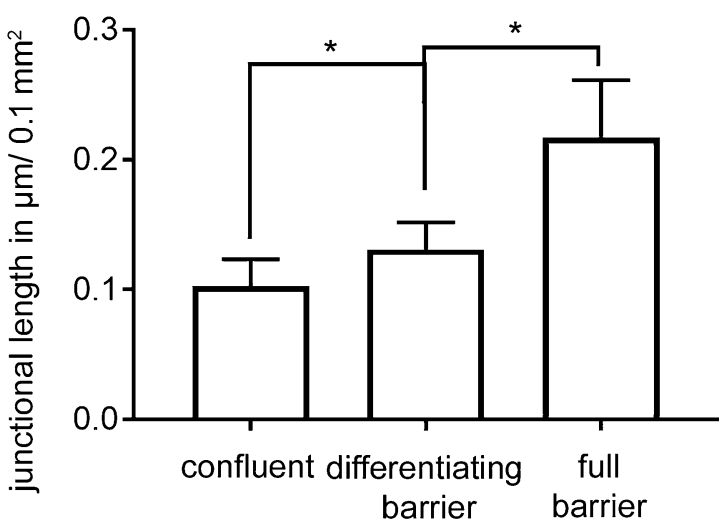

Fig. 2 Changes in cell numbers and junctional length during differentiation. a The changes in the number of cells during the differentiation of clone 1 are shown. The number of cells $/ 0.1 \mathrm{~mm}^{2}$ steadily increased until day 14 , where a maximum of $211 \pm 3$ per $0.1 \mathrm{~mm}^{2}$ was reached $(n=8, * p<0.05$, one-way ANOVA). bLikewise, the average number of cells per $0.1 \mathrm{~mm}^{2}$ of clone 2 rose through the different states of differentiation $(n=8, * p<0.05$, one-way ANOVA).
Changes in TEER were reciprocal to changes in junctional length or cell numbers only in the early stage after confluence

To elucidate whether the changes in cell numbers and junctional length would be the critical event that explained our observation of undulating TEER values after confluence, we plotted the TEER values from the Caco 2 clone 2 cell culture models against the average number of cells counted and the circumferential junctional length in an area $0.1 \mathrm{~mm}^{2}$ (Fig. 3a, b). This graphical representation provided a clearer view of how the growing number of cells and the junctional length correlated with the measured TEER values. Following the hypothesis of a resistor with a growing surface area, the increasing junctional length should then lead to reciprocal changes of the TEER. This would be only
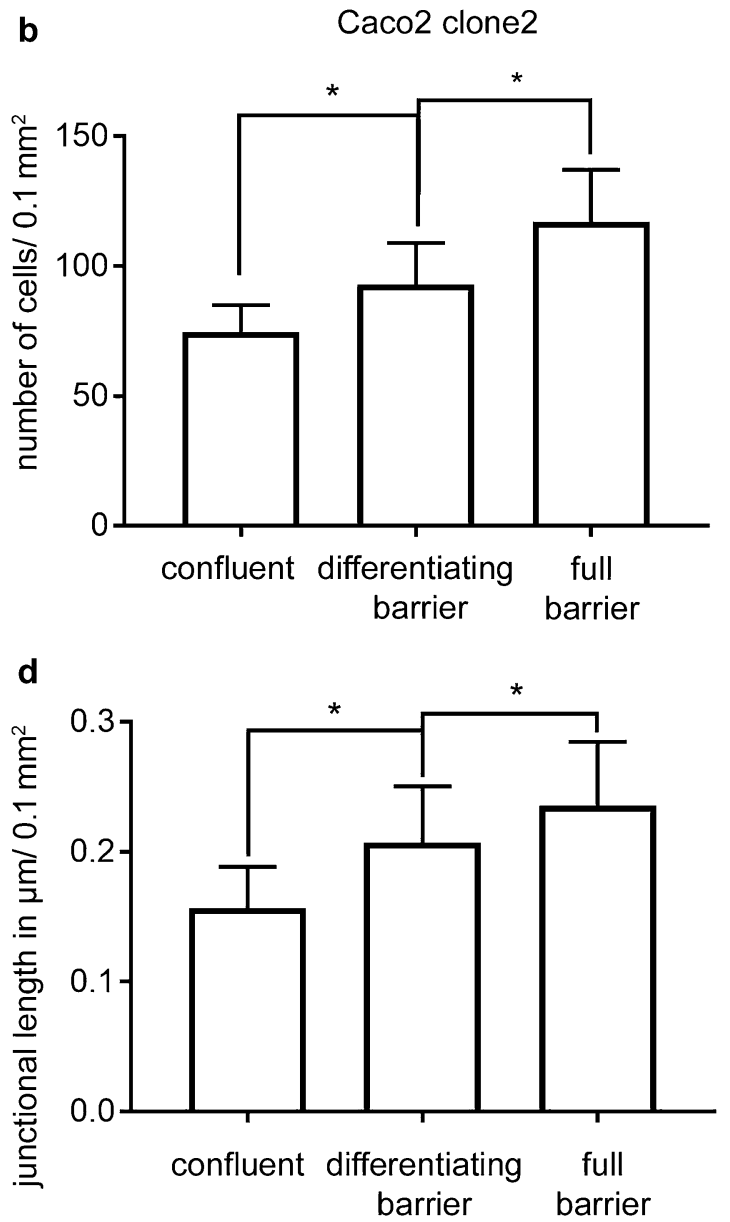

c. The increase in cell number was paralleled by an increase of the junctional length $/ \mu \mathrm{m}$. The junctional length of clone 1 increased from $0.10 \pm 0.03 \mu \mathrm{m} / 0.1 \mathrm{~mm}^{2}$ to $0.22 \pm 0.04 \mu \mathrm{m} / 0.1 \mathrm{~mm}^{2}$ at the state of full barrier $(n=8, * p<0.05$, one-way ANOVA). d. Similarly, in clone 2 the junctional length expanded over time $(n=8, * p<0.05$, one-way ANOVA) 
a

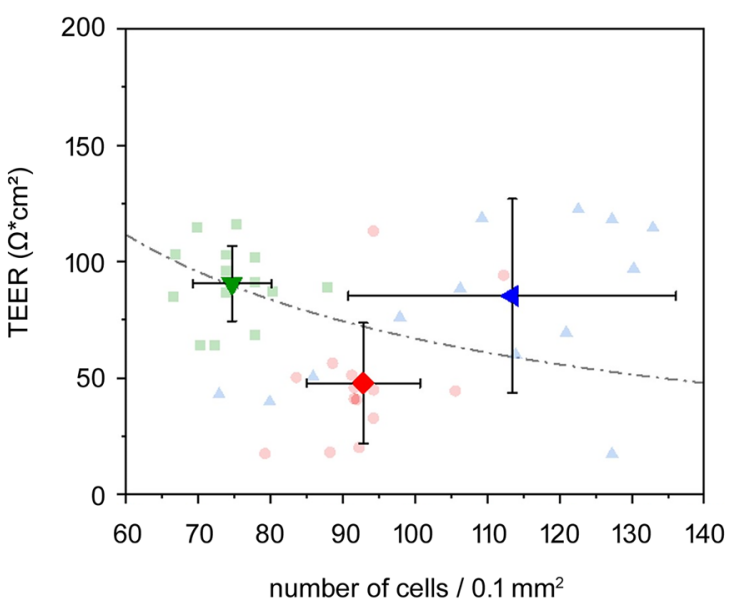

C

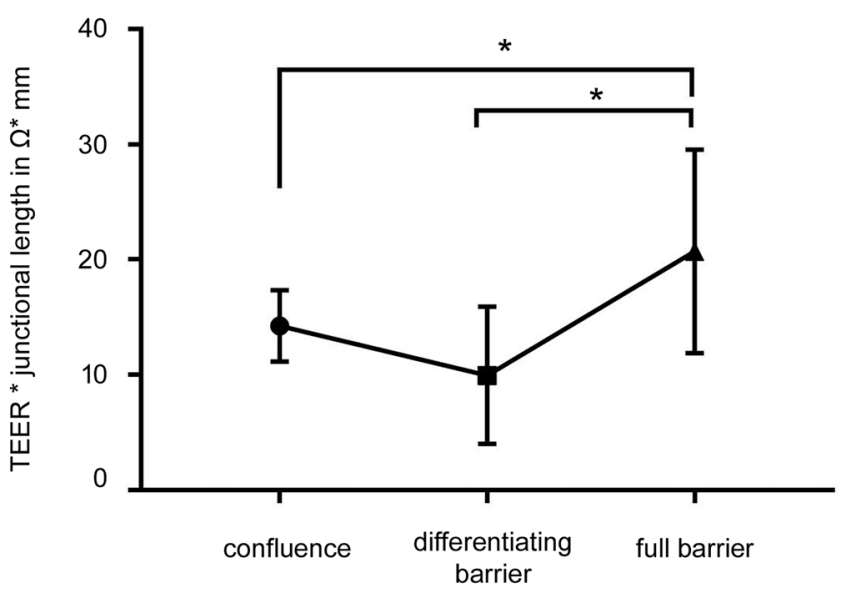

b

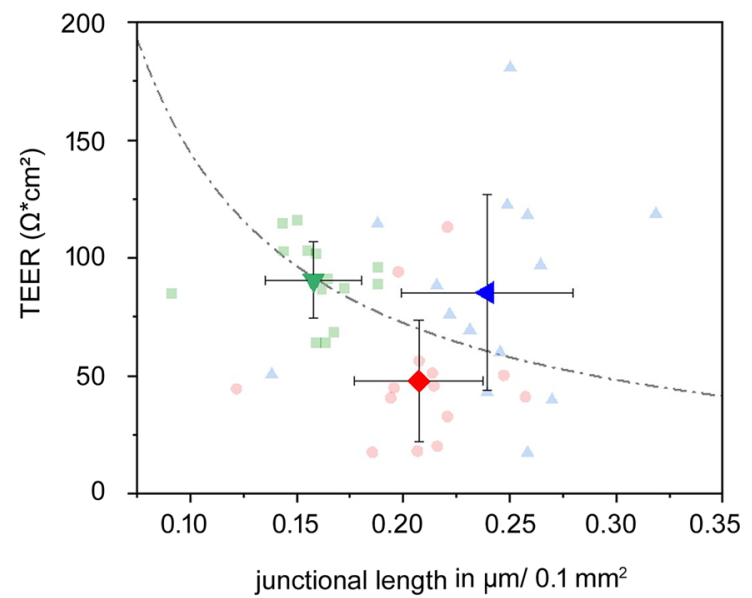

Fig. 3 Changes of TEER and corresponding cell numbers and junctional length. a A plot of the individual transepithelial electric resistance (TEER) of clone 2 to the corresponding number of cells is shown. This demonstrated that, from confluence to the state of differentiating barrier, the values dropped reciprocal to the increase in number of cells, then increased to the level of full barrier properties, though the number of cells was even higher than in previous states. If the TEER solely depended on cell numbers at the state of full barrier, we would have expected values that followed the ideal logarithmic curve. b Similar effects were observed when we drafted TEER

the case if the resistance per length of the cell-cell junctions remained constant. To address this, we multiplied the individual TEER values in $\Omega \mathrm{cm}^{2}$ with the corresponding junctional length in $\mu \mathrm{m} / 0.1 \mathrm{~mm}^{2}$ of the same experiment. This revealed that, this calculated value from state of confluence $(14.2 \pm 3.1 \Omega \mathrm{mm})$ to the differentiating barrier $(10.0 \pm 5.9 \Omega \mathrm{mm})$ did not show an significant changes. However, it increased to $20.7 \pm 8.8 \Omega \mathrm{mm}$ under full barrier conditions, indicating that during that phase the paracellular resistance per junctional length changed dramatically. Therefore, our calculations indicated that the junctional length/ area directly affects TEER measurements only at the very to the corresponding measurements of clone 2 of junctional length in $\mu \mathrm{m} / 0.1 \mathrm{~mm}^{2}$, where the increase of TEER under full barrier properties also did not follow a reciprocal curve. c. To differentiate if the TEER per cell-cell junction would remain constant, we multiplied the TEER with the corresponding junctional length of the same experiment. This revealed that, during the initial differentiation from confluence to differentiating barrier, the TEER per junctional length stayed nearly constant from $14.2 \pm 3.1 \Omega \mathrm{mm}$ to $10.0 \pm 5.9 \Omega \mathrm{mm}$, while a significant increase to $20.7 \pm 8.8 \Omega \mathrm{mm}$ was observed under full barrier conditions $(n=8, * p<0.05$, two-way ANOVA)

early stage of junctional maturation, when tight junctions are not yet functional. This explains our transitional drop after cells were confluent. However, when junctional differentiation starts, the dynamics of the TEER rather reflect barrier maturation, whereas junctional length becomes negligible.

\section{Summary and conclusion}

Taken together, we observed that during the differentiation of a confluent cell monolayer the TEER initially decreased, while permeability of $4 \mathrm{kDa}$ FITC-dextran and 


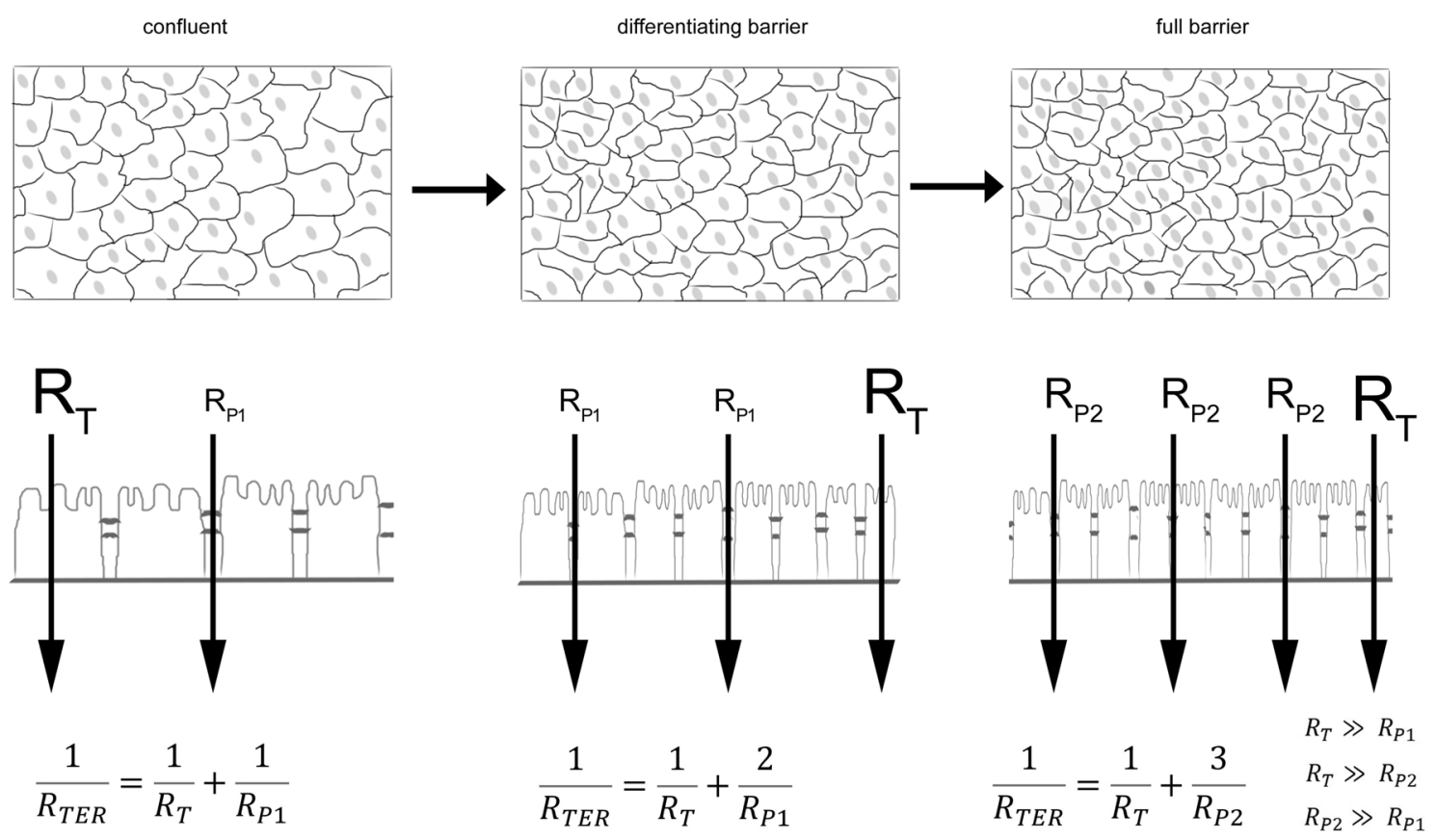

Fig. 4 Schematic synopsis of effect of junctional length and TEER. A schematic synopsis of the observations is shown. At the state of confluence, the overall TEER was determined by the lower resistor for the paracellular pathway $\left(\mathrm{R}_{\mathrm{P} 1}\right)$ compared with the resistor of the transcellular pathway $\left(\mathrm{R}_{\mathrm{T}}\right)$. During differentiation, an increase in number of cells and junctional length influenced the overall TEER until the paracellular resistor $\mathrm{R}_{\mathrm{P} 2}$ sufficiently increased when full barrier prop- erties were achieved. The effect is clearer if you assume that TEER is following a parallel circuit. The equation to determine the TEER in such a parallel circuit clearly demonstrates that an increase in junctional length by the factor 2 leads to a reduction of TEER by $50 \%$ if all factors determining the resistor $R_{P 1}$ remain constant and $R_{T}$ is distinctly larger than $R_{p}$. This effect is diminished if $R_{P 2}$ is larger than the initial $R_{P 1}$ immunocytochemistry of cellular junctions would suggest a steady increase of TEER. Our data clearly show that the growing number of cells and, thus, junctional length dominate the TEER values in the early stages of the maturation process (confluent-differentiating barrier). However, in the later stages of this process (differentiating barrier-full barrier), the strength of the intercellular connections is increasing, and despite rapidly increasing cell numbers and junctional length, a continuous strengthening of the barrier can be observed, resulting in an increase in paracellular resistance and, thus, rising TEER values (Fig. 4). This is important when assessing barrier maturation by TEER since confluent monolayers may exhibit dynamics that may lead to misinterpretations after having reached confluence. According to our observation reported here, this depends on strong alterations of overall junctional length within monolayers. Therefore, we strongly recommend thorough assessment of morphology and maturation state of junctions in parallel when TEER measurements are applied for barrier measurements.

Acknowledgements The authors are grateful to Eva Riedel and Veronika Heimbach for their technical assistance.
Author contributions M.M. and T.S. conceived and designed the research; M.M. and F.K. performed experiments; T.S., F.K., N.S., and M.M. analyzed data and interpreted results of experiments; M.M. and T.S. prepared figures; T.S., F.K., J.H., N.S., and M.M. drafted, edited, and revised the manuscript; T.S., F.K., J.H., N.S., and M.M. approved the final version of the manuscript.

Funding Open Access funding enabled and organized by Projekt DEAL. The study was supported by the Interdisziplinäre Zentrum für Klinische Forschung IZKF Z-2/63 to M. Meir and the DFG priority program 1782 SCHL1962/2-2 to N. Schlegel.

Data availability All data generated or analyzed during this study are included in this published article.

\section{Declarations}

Conflict of interest The authors declare that they have no conflict of interest.

Open Access This article is licensed under a Creative Commons Attribution 4.0 International License, which permits use, sharing, adaptation, distribution and reproduction in any medium or format, as long as you give appropriate credit to the original author(s) and the source, provide a link to the Creative Commons licence, and indicate if changes were made. The images or other third party material in this article are 
included in the article's Creative Commons licence, unless indicated otherwise in a credit line to the material. If material is not included in the article's Creative Commons licence and your intended use is not permitted by statutory regulation or exceeds the permitted use, you will need to obtain permission directly from the copyright holder. To view a copy of this licence, visit http://creativecommons.org/licenses/by/4.0/.

\section{References}

Blume LF, Denker M, Gieseler F, Kunze T (2010) Temperature corrected transepithelial electrical resistance (TEER) measurement to quantify rapid changes in paracellular permeability. Pharmazie 65(1):19-24

Bowman PD, Ennis SR, Rarey KE, Betz AL, Goldstein GW (1983) Brain microvessel endothelial cells in tissue culture: a model for study of blood-brain barrier permeability. Ann Neurol 14(4):396402. https://doi.org/10.1002/ana.410140403

Briske-Anderson MJ, Finley JW, Newman SM (1997) The influence of culture time and passage number on the morphological and physiological development of Caco-2 cells. Proc Soc Exp Biol Med 214(3):248-257. https://doi.org/10.3181/00379727-214-44093

Chang YS, Munn LL, Hillsley MV, Dull RO, Yuan J, Lakshminarayanan S, Gardner TW, Jain RK, Tarbell JM (2000) Effect of vascular endothelial growth factor on cultured endothelial cell monolayer transport properties. Microvasc Res 59(2):265-277. https:// doi.org/10.1006/mvre.1999.2225

Duffy SL, Murphy JT (2001) Colorimetric assay to quantify macromolecule diffusion across endothelial monolayers. Biotechniques 31(3):495-496. https://doi.org/10.2144/01313st02 (PMID: 11570492)

Flemming S, Burkard N, Renschler M, Vielmuth F, Meir M, Schick MA, Wunder C, Germer CT, Spindler V, Waschke J, Schlegel $\mathrm{N}$ (2015) Soluble VE-cadherin is involved in endothelial barrier breakdown in systemic inflammation and sepsis. Cardiovasc Res 107(1):32-44. https://doi.org/10.1093/cvr/cvv144

Hering NA, Luettig J, Krug SM, Wiegand S, Gross G, van Tol EA, Schulzke JD, Rosenthal R (2017) Lactoferrin protects against intestinal inflammation and bacteria-induced barrier dysfunction in vitro. Ann N Y Acad Sci 1405(1):177-188. https://doi.org/10. 1111/nyas. 13405

Ivanov AI, Naydenov NG (2013) Dynamics and regulation of epithelial adherens junctions: recent discoveries and controversies. Int Rev Cell Mol Biol 303:27-99. https://doi.org/10.1016/B978-012-407697-6.00002-7

Meir M, Flemming S, Burkard N, Bergauer L, Metzger M, Germer CT, Schlegel N (2015) Glial cell line-derived neurotrophic factor (GDNF) promotes barrier maturation and wound healing in intestinal epithelial cells in vitro. Am J Physiol Gastrointest Liver Physiol 00357:02014. https://doi.org/10.1152/ajpgi.00357.2014

Meir M, Burkard N, Ungewiss H, Diefenbacher M, Flemming S, Kannapin F, Germer CT, Schweinlin M, Metzger M, Waschke J, Schlegel N (2019) Neurotrophic factor GDNF regulates intestinal barrier function in inflammatory bowel disease. J Clin Invest. https://doi.org/10.1172/JCI120261

Meir M, Salm J, Fey C, Schweinlin M, Kollmann C, Kannapin F, Germer CT, Waschke J, Beck C, Burkard N, Metzger M, Schlegel N (2020) Enteroids generated from patients with severe inflammation in Crohn's disease maintain alterations of junctional proteins. J Crohns Colitis. https://doi.org/10.1093/ecco-jcc/jjaa0 85

Prot-Bertoye C, Houillier P (2020) Claudins in renal physiology and pathology. Genes. https://doi.org/10.3390/genes11030290

Rezaee F, Georas SN (2014) Breaking barriers. New insights into airway epithelial barrier function in health and disease. Am J Respir Cell Mol Biol 50(5):857-869. https://doi.org/10.1165/rcmb. 2013-0541RT

Robilliard LD, Kho DT, Johnson RH, Anchan A, O'Carroll SJ, Graham ES (2018) The Importance of multifrequency impedance sensing of endothelial barrier formation using ECIS technology for the generation of a strong and durable paracellular barrier. Biosensors. https://doi.org/10.3390/bios8030064

Sayoc-Becerra A, Krishnan M, Fan S, Jimenez J, Hernandez R, Gibson K, Preciado R, Butt G, McCole DF (2020) The JAK-inhibitor tofacitinib rescues human intestinal epithelial cells and colonoids from cytokine-induced barrier dysfunction. Inflamm Bowel Dis 26(3):407-422. https://doi.org/10.1093/ibd/izz266

Schlegel N, Meir M, Heupel WM, Holthofer B, Leube RE, Waschke J (2010) Desmoglein 2-mediated adhesion is required for intestinal epithelial barrier integrity. Am J Physiol Gastrointest Liver Physiol 298(5):G774-783. https://doi.org/10.1152/ajpgi.00239.2009

Schlegel N, Leweke R, Meir M, Germer CT, Waschke J (2012) Role of NF-kappaB activation in LPS-induced endothelial barrier breakdown. Histochem Cell Biol 138(4):627-641. https://doi.org/10. 1007/s00418-012-0983-7

Schlegel N, Boerner K, Waschke J (2021) Targeting desmosomal adhesion and signalling for intestinal barrier stabilization in inflammatory bowel diseases-Lessons from experimental models and patients. Acta Physiol (Oxf) 231(1):e13492. https://doi.org/10. 1111/apha.13492 (Epub 22 May 2020, PMID: 32419327)

Schulzke JD, Gunzel D, John LJ, Fromm M (2012) Perspectives on tight junction research. Ann N Y Acad Sci 1257:1-19. https://doi. org/10.1111/j.1749-6632.2012.06485.x

Spindler V, Meir M, Vigh B, Flemming S, Hutz K, Germer CT, Waschke J, Schlegel N (2015) Loss of desmoglein 2 contributes to the pathogenesis of Crohn's disease. Inflamm Bowel Dis. https:// doi.org/10.1097/MIB.0000000000000486

Srinivasan B, Kolli AR, Esch MB, Abaci HE, Shuler ML, Hickman JJ (2015) TEER measurement techniques for in vitro barrier model systems. J Lab Autom 20(2):107-126. https://doi.org/10.1177/ 2211068214561025

Zelman A (1972) Membrane permeability. Generalization of the reflection coefficient method of describing volume and solute flows. Biophys J 12(4):414-419. https://doi.org/10.1016/S00063495(72)86093-4

Zucco F, Batto AF, Bises G, Chambaz J, Chiusolo A, Consalvo R, Cross H, Dal Negro G, de Angelis I, Fabre G, Guillou F, Hoffman S, Laplanche L, Morel E, Pincon-Raymond M, Prieto P, Turco L, Ranaldi G, Rousset M, Sambuy Y, Scarino ML, Torreilles F, Stammati A (2005) An inter-laboratory study to evaluate the effects of medium composition on the differentiation and barrier function of Caco-2 cell lines. Altern Lab Anim 33(6):603-618. https://doi.org/10.1177/026119290503300618

Publisher's Note Springer Nature remains neutral with regard to jurisdictional claims in published maps and institutional affiliations. 